IJCHM

31,12

4520

Received 3 February 2019

Revised 26 April 2019

28 June 2019

Accepted 5July 2019

\section{Standing out from the crowd - an exploration of signal attributes of Airbnb listings}

\author{
Bin Yao \\ School of Economics, Liaoning University, Shenyang, China \\ Richard T.R. Qiu \\ Department of Integrated Resort and Tourism Management, \\ Faculty of Business Administration, University of Macau, Taipa, Macao \\ Daisy X.F. Fan \\ eTourism Lab, International Centre for Tourism and Hospitality Research, \\ Bournemouth University, Poole, UK \\ Anyu Liu \\ School of Hospitality and Tourism Management, University of Surrey, \\ Guildford, UK, and \\ Dimitrios Buhalis \\ eTourism Lab, International Centre for Tourism and Hospitality Research, \\ Bournemouth University, Poole, UK
}

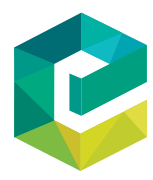

International Journal of Contemporary Hospitality Management Vol. 31 No. 12, 2019 pp. $4520-4542$ pp. 4520-4542 0959-6119 DOI 10.1108/IJCHM-02-2019-0106

\begin{abstract}
Purpose - Due to product diversity, traditional quality signals in the hotel industry such as star ratings and brand affiliation do not work well in the accommodation booking process on the sharing economy platform. From a suppliers' perspective, this study aims to apply the signaling theory to the booking of Airbnb listings and explore the influence of quality signals on the odds of an Airbnb listing being booked.
\end{abstract}

Design/methodology/approach - A binomial logistic model is used to describe the influences of different attributes on the market demand. Because of the large sample size, sequential Bayesian updating method is utilized in hospitality and tourism field for the first attempt.

Findings - Results show that, in addition to host-specific information such as "Superhost" and identity verification, attributes including price, extra charges, region competitiveness and house rules are all effective signals in Airbnb. The signaling impact is more effective for the listings without any review comments.

Originality/value - This study contributes to the literature by incorporating the signaling theory in the analysis of booking probability of Airbnb accommodation. The research findings are valuable to hosts in

(C) Bin Yao, Richard T.R. Qiu, Daisy X.F. Fan, Anyu Liu and Dimitrios Buhalis. Published by Emerald Publishing Limited. This article is published under the Creative Commons Attribution (CC BY 4.0) licence. Anyone may reproduce, distribute, translate and create derivative works of this article (for both commercial \& non-commercial purposes), subject to full attribution to the original publication and authors. The full terms of this licence may be seen at http://creativecommons.org/licences/by/4.0/ legalcode 
improving their booking rates and revenue. In addition, government and industrial management organizations can have more efficient strategy and policy planning.

Keywords Signaling theory, Big data, Airbnb, Binomial logistic model, Booking probability, Sequential Bayesian updating, Sharing economy

Paper type Research paper

\section{Introduction}

Hotels, as the most common type of accommodation that tourists use, have been extensively investigated in an effort to develop the selection criteria of hotels at both the individual level through the consumer behavior perspective (Dolnicar and Otter, 2003) and the aggregate supply-demand perspective (Song et al., 2011). It has been long acknowledged that room and service quality are key determinants to accommodation selection (Chu and Choi, 2000). However, thus quality cannot be experienced before the purchase. Hotels have to release observable and creditable signals to convince the customers regarding the room and service quality (Abrate et al., 2011). Quality of hotels can be indicated by either star rating and brand affiliation which are standardized and reputable (Oskam and Boswijk, 2016), or online review comments on recognized platforms such as TripAdvisor and Booking.com (Möhlmann, 2016). Such signals could significantly reduce the information asymmetry between consumers and suppliers and facilitate the booking of hotels (Abrate et al., 2011; Ponte et al., 2015).

Airbnb provides different experiences compared with traditional hotels to accommodate visitors who seek interactions, home feelings and local authenticity (Guizzardi et al., 2017). Motivated by such needs, Airbnb listings are set to offer heterogeneous experience, which are different from the standardized services provided by traditional hotels. The heterogeneity nature of Airbnb listings calls the effectiveness of the traditional signals of service quality into question. The information asymmetry between guests and hosts in Airbnb is more severe than traditional hotels. Guests have to go through a complicated process to sort out trustable signals from the information uploaded by the hosts on Airbnb platform. From the hosts' perspective, on the other hand, it is also challenging for them to figure out the listing attributes that could be more effective in signaling the service quality, improving the booking probability, and providing a prominent market position among numerous competitors on the same platform.

While there are in-depth insights in terms of quality signals of traditional hotels, no comprehensive picture is provided regarding the impact of quality signals on the listing performance in Airbnb market. This study contributes to the literature by incorporating the signaling theory in the analysis of booking probability of Airbnb accommodation. It provides insights of quality signaling mechanism in the Airbnb market by estimating and examining the influence of various attributes of Airbnb listings on its market demand. The research findings not only enrich the literature of signaling theory in the Airbnb context, but also provide valuable practical implications to current and potential hosts in understanding the demand of their listings and improving their booking rates and revenue. In addition, government and industrial management organizations can have more efficient strategy and policy planning.

\section{Literature review}

\subsection{Asymmetric information and signaling theory}

Deviating from the perfect information assumption in economic theories, asymmetric information describes a scenario in economic transactions which one party possesses more 
IJCHM

31,12

or better information than the other. Asymmetric information leads to imbalance of power in the economic transactions and usually results in market failure (Akerlof, 1970). In the accommodation booking context, if the guests could not obtain quality information of each room, they will offer a price according to the average room quality in the market. Assuming positive correlation between room quality and cost, the offered price is not likely to cover the cost of high-quality rooms. Therefore, high quality rooms will quit the market due to unprofitability and the average room quality in the market will decrease along time. This "bad drives out good" type of problem harms both the guests and the room suppliers due to less and worse options and lower profitability, respectively.

In the above context, where the service and room quality can hardly be revealed before the purchase, guests are usually the ignorant party. They are, therefore, highly motivated to conduct information search to reduce the disadvantage brought about by information asymmetry. While guests aim to reduce information asymmetry through multiple channels, suppliers have also the incentive to signal the quality of their goods and services. According to the signaling theory in economics (Spence, 1973), it is vital for suppliers to convince consumer about the quality of their products. Among others, quality certifications are popular strategies for suppliers to reduce information asymmetry (Chen and Xie, 2017; Nicolau and Sellers, 2010).

\subsection{Quality signals in hotel industry}

Prior to the emergence of sharing economy, research in the field of tourism accommodation primarily concentrated on revealing the effects and relative importance of various hotel attributes on guests' selection. (Dolnicar and Otter, 2003; Chow et al., 1995; Callan, 1995, 1998). Some of the attributes are observable such as location, access, and facilities including "rooms" in Dolnicar and Otter (2003), "physical appearance" in Chow et al. (1995) and "tangible attributes" in Callan $(1995,1998)$, whereas some of the attributes are unobservable, such as "image", "services" and "reputation" (Callan, 1995, 1998; Chow et al., 1995; Dolnicar and Otter, 2003). Abrate et al. (2011) argued that the unobserved service quality is usually indicated by quality signals such as star rating and brand affiliation in hotels.

With the widespread usage and the emerging popularity of the internet, customers have more information sources than before, especially through diverse online platforms (Buhalis and O'Connor, 2005). Hotel features that are provided through the internet, such as "terms and conditions" are found to have a significant influence on the online booking intention of customers (Chen et al., 2011; Law and Wong, 2010). Li et al. (2016) and Wang et al. (2015) argue that hotel website quality, including usability, functionality, security and privacy of the website, can predict booking intention.

Online ratings generated by former guests and provided on third party websites are found to be essential to the marketing of hotels. In a study on the hotel sales in Paris and London, Ögüt and Onur Taş (2012) reveal a positive link between hotel sales and the online customer ratings. They also find that managers in higher star hotels can utilize the positive customer ratings and generate more revenue in comparing with the scenario of lower star hotels. Online ratings and comments from previous guests are also found to reflect the reputation of the hotel and mitigate the negative impact of low accessibility in the island tourism context (Yang et al., 2016). As argued by Yang et al. (2016), social media is a quality signal factor and plays a moderating role on the relationship between market accessibility and hotel price. The platform on which the online ratings and comments are published is also important. Ratings are perceived to be more reliable if they are published by wellrecognized social media, such as TripAdvisor, or they are linked to actual reservations such as those on Booking.com (Möhlmann, 2016). Casaló et al. (2015) further assert that hotels 
generate more favorable attitude if they appear in the best hotels lists in social media. Kim and Park (2017) suggest that social media review ratings have stronger power than traditional attributes to predict hotel performance.

Yang et al. (2016) reveal that, benefited from the development of information and communication technology, online review comments have been widely used by guests as quality signals in booking behaviors. Kim and Park (2017) further argue that nowadays, eword of mouth (e.g. online reviews and review ratings) plays a more important role than traditional customer satisfaction in influencing consumer purchase behavior. Peer to peer review comments are perceived as an important signal in the decision-making process of customers, when they book hotels online (Au et al., 2014; Ladhari and Michaud, 2015; Yu et al., 2016; Zhao et al., 2015). Positive and negative comments have different effects on the decision-making process of customers (Tsao et al., 2015).

\subsection{Quality signals in Airbnb}

Although quality signals in Airbnb market are investigated by researchers (Chen and Xie, 2017; Dogru and Pekin, 2017; Gibbs et al., 2018; Li et al., 2016; Wang and Nicolau, 2017), it is noticed that most of their studies focus on the impact of quality signals on pricing. Factors including host attributes, property attributes, house rules, review ratings and services and amenities are effective signals used by guests and have significant correlation with price (Li et al., 2016; Wang and Nicolau, 2017). Images of the listing are found to be important signals in determining the booking behaviors of consumers on Airbnb (Dogru and Pekin, 2017). In particular, room pictures (Rahimi et al., 2016) and host photos (Ert et al., 2016) exhibit significant influence on the market demand of the Airbnb listings. In addition to photos, Teubner et al. (2017) and Xie and Mao (2017) suggest that a long duration of membership of the host can enhance the trust of guest and play as a signal in pricing. Interestingly, while review rating is generally considered to be a signal that is positively correlated with quality, Gibbs et al. (2018) find a negative but marginal association between number of reviews and room price.

It is undeniable that the abovementioned studies contribute to the understanding of Airbnb phenomenon. However, the results should be considered with cautions. According to signaling theory, price itself is also an effective signal influencing the behavior of the consumer (Wolinsky, 1983, p.647). The impact of price as a signal and the relationship between quality signals and listing behaviors in Airbnb sector have been overlooked. Therefore, it is important to retailor the signaling theory and explore the effective quality signals in the Airbnb context.

\subsection{Research gaps}

As a market pioneer in peer-to-peer accommodation service, the Airbnb hosts are encouraged to make guests feel at home and bond with the local environment. Compared with the standard service provided by hotels, room settings and services of Airbnb are different from listing to listing. This feature leads to significant heterogeneity in terms of the quality of the listings. The quality signals used by guests in hotel sector may be neither appropriate nor efficient, because in Airbnb market, the options for guests are much more than those provided in the hotel market (Chen and Xie, 2017; Gutt and Herrmann, 2015). Thus, the potential guests are utilizing different quality signals to identify the good listings.

Throughout the literature of online booking of both hotels and Airbnb, the existence of information asymmetry is well recognized. Online reviews and ratings from peer-guests are popular signals through which guests predict products or services quality in both hotel and Airbnb markets (Senecal and Nantel, 2004; Yang et al., 2016). Abrate et al. (2011), and Henley 
IJCHM 31,12

et al. (2004) show that star ratings and brand affiliations are frequently used by guests as quality signals for hotel room booking. However, such signals do not exist on the Airbnb platform. As noticed by Gutt and Herrmann (2015), with the peer-to-peer nature of the Airbnb platform and the heterogeneous guest groups, the determinants of Airbnb booking probabilities differ from those of traditional hotels.

To bridge the gaps, a comprehensive list of Airbnb listing attributes is examined to explore their influence on the booking probability of Airbnb listings. In particular, the attributes are analyzed on their ability of indicating room and service quality of Airbnb listings. According to different level of information asymmetry, the sampled listings are differentiated into two subgroups, namely "with review" group and "no review" group. The impacts of listing attributes are discussed and compared accordingly within and between two subgroups. Methodologically, to handle the big volume of data, the current study represents the first attempt of using sequential Bayesian updating approach in hospitality and tourism field.

\section{Methodology}

\subsection{Data}

The data of Airbnb listings in London are retrieved from Insideairbnb.com. After removing redundant and irrelevant variables, the pairwise correlations among all variable-pairs were checked. Variable-pairs were either combined or have one variable omitted if they have similar meaning and exhibit high correlation. The latitude and longitude coordinates of listings are used to calculate the distance from the listing to the city center and to the nearest tube station. The two calculated variables capture the location of the listings and the convenience of the listings, respectively. In order to capture the spatial spillover effect, the total number of neighboring listings and the number of available neighboring listings are calculated, for each listing, every calendar day. A distance of $5 \mathrm{~km}$ is adopted as the criteria for two listings to be identified as neighbors (Yang et al., 2012). The neighboring variables not only capture the popularity of the region but also the potential competition within in the region. Thirty-four variables are eventually considered as the attributes that influence the booking probabilities of Airbnb listings. Differentiated by their ability on signaling the quality, the 34 attributes were labeled as functional attributes, signal attributes, or dual attributes. The categorization is inspired by the classifications used in marketing literature (Jacoby et al., 1971; Kostyra et al., 2016). Functional attributes include the features of Airbnb listings that are directly consumed by the guests or directly related to the consumption process. Signal attributes are provided by the hosts or the platform as quality or value indicators. Dual attributes are listing attributes that exhibit features of both functional attributes and signal attributes. The labeling of the listing attributes is further validated by a Delphi survey with five academic professionals and three current Airbnb hosts. After three rounds of anonymous surveys, eight experts achieved agreement regarding the categorization of the attributes. The final categorization is presented in Figure 1.

In the retrieved dataset, listings with unreasonable length of availability (e.g. fully booked for the next 365 days) and with incomplete information were omitted. Although the booking information of 365 days in advance could be accessed, the data pointed further from the current time (i.e. the time of data retrieval) contained limited information on the market demand. Since most people are concerned about room reservation around 30 days prior to the stays (Chen and Schwartz, 2008), the current research used up to 31-day-ahead booking information as the sample period. The final dataset contains booking information of 41,124 listings from 5 March 2017 to 4 April 2017 (31 days), resulting in a panel dataset with $1,274,844$ observations (41,124 listings $\times 31$ days). 
Online reviews play as a key signal in the booking process of guests (Yu et al., 2016; Zhao et al., 2015). Attributes other than online reviews may influence the market demand differently with or without the presence of review information. The sample was divided further into two subsamples, while estimating the influence of various attributes on the market demand. The first subsample, namely the "with review" group, contained 30,112 listings that had at least one review in the past. The second subsample, namely the "no review" group, contained 11,012 listings that had no review in the online system. The estimation of the two subsamples was conducted separately, as the model of "with review" group had four extra review-related variables (i.e. total number of the reviews, total score of the reviews, number of reviews per month, and months since previous review). The descriptive statistics of the two subsamples are provided in the Appendices.

\subsection{Binomial logistic model}

A binomial logistic model is specified to characterize the influence of listing attributes on the market demand. The market demand of an Airbnb listing is measured by the probability of the listing being booked. The equation (1) describes the probability of observed data given a parameter vector:

$$
p\left(y_{i, t}=1, \boldsymbol{x}_{\boldsymbol{i}, t} \mid c_{t}, \boldsymbol{\beta}\right)=\frac{\exp \left\{c_{t}+\boldsymbol{x}_{\boldsymbol{i}, t}^{\prime} \boldsymbol{\beta}\right\}}{1+\exp \left\{c_{t}+\boldsymbol{x}_{\boldsymbol{i}, t}^{\prime} \boldsymbol{\beta}\right\}},
$$

where $y_{i, t}$ indicates the booking status of listing $i$ on date $t$, which is equal to one if listing $i$ is booked on date $t$ and zero otherwise; $\boldsymbol{x}_{\boldsymbol{i}, t}$ is a vector of attributes of listing $i$ observed on date $t ; c_{t}$ is a time-varying constant that captures the time effect on booking probability of Airbnb 
IJCHM

31,12

listings; and $\boldsymbol{\beta}$ is a vector of coefficients evaluating the relative importance of various attributes of the listings on booking probability.

A likelihood function can, therefore, be written as:

$$
\ell\left(c_{t}, \boldsymbol{\beta} \mid y_{i, t}, \boldsymbol{x}_{i, t}\right)=\prod_{t} \prod_{i} p\left(y_{i, t}=1, \boldsymbol{x}_{i, t} \mid c_{t}, \boldsymbol{\beta}\right)^{y_{i, t}}\left[1-p\left(y_{i, t}=1, \boldsymbol{x}_{i, t} \mid c_{t}, \boldsymbol{\beta}\right)\right]^{1-y_{i, t}} .
$$

With observed data $\left(y_{i, t}, \boldsymbol{x}_{i, t}\right)$, the likelihood function can be maximized relative to the unknown parameter vector $c_{t}$ and $\boldsymbol{\beta}$.

\subsection{Sequential Bayesian updating}

In the current study, Bayesian approach is utilized to handle the large volume of data. One of the challenges in managing large volume of data is the difficulty in data storage and computation. In frequentist statistics, model estimation is statistical inference process from the sample (data) to the population (reality), and the data are commonly examined all together at once. The storage and computational burdens on computers increase exponentially as the volume of the data increases. In contrast, Bayesian statistics consider model estimation as an updating process of prior beliefs based on observed data. The "updating" concept makes Bayesian statistics very handy in handling large dataset. The data can be partitioned into manageable subsets and the updating process can be conducted sequentially.

In Bayesian statistics, prior distribution is described as the current state of knowledge regarding parameters and posterior distribution is the updated belief on parameter values after observing some data. Therefore, after estimation and when new data become available, the estimated posterior distribution can be regarded as a new prior distribution. A new posterior distribution can be generated with the new data. Crucially, while estimating the new posterior distribution, the calculation of likelihood using old data would not be necessary because information regarding the old data is contained sufficiently in the previous posterior distribution. Through sequential Bayesian updating, the large dataset can be partitioned into several smaller and manageable subsets. The model fitting can be performed sequentially, using the posterior distribution of each subset as the prior distribution for the next subset. Some theoretical discussions and examples on sequential Bayesian updating can be found in Oravecz et al. (2016).

In the current study, the entire dataset is partitioned according to time, with each subset consists of the booking information of one calendar day. For each subset, following the classical Bayesian presentation, the posterior distribution of parameter is proportional to the product of the likelihood function, $\ell\left(c_{t}, \boldsymbol{\beta} \mid y_{i, t}, \boldsymbol{x}_{i, t}\right)$ and the prior distribution, $p\left(c_{t}, \boldsymbol{\beta}\right)$ :

$$
p\left(c_{t}, \boldsymbol{\beta} \mid y_{i, t}, \boldsymbol{x}_{i, t}\right) \propto \ell\left(c_{t}, \boldsymbol{\beta} \mid y_{i, t}, \boldsymbol{x}_{i, t}\right) p\left(c_{t}, \boldsymbol{\beta}\right) .
$$

The prior distribution in equation (3) is sampled using Markov chain Monte Carlo (MCMC) methods, in particular the Metropolis-Hastings algorithm. Uninformative prior (mean $=0$, standard deviation $=100$ ) is used in the estimation of the first subset and informative prior equal to the previous posterior is adopted subsequently. Updating of the posterior distributions of the parameters does not involve $c_{t}$. The series representing the time-specific constant, $\left\{c_{t}, c_{t+1}, \ldots\right\}$, is estimated successively using data from each subset with uninformative prior. 


\section{Findings and discussions}

\subsection{The general estimation results}

Model predictions are generated for both the "with review" and the "no review" groups and presented in Figure 2. The proportion of the listings being booked is adopted as the actual booking rate for each group. Predictions are generated by logit function using the means of posterior distribution of the parameters. The mean absolute percentage error (MAPE), which is the most widely used measurement of forecasting error in the tourism and hospitality field (Wu et al., 2017), is employed to evaluate the predictability of the models. The predictions for the "with review" group are very accurate with a MAPE of 2.84 per cent. The predictions for the "no review" group are slightly worse than its counterpart with a MAPE of 9.60 per cent. Both models show accurate predictability (with MAPE below 10 per cent), indicating the good explanatory power of the models employed. Without the information from the review comments, the "no review" group exhibit higher degree of information asymmetry. Increased randomness is therefore revealed in the booking process in thus group, and further leads to the lower prediction accuracy in the "no review" group. The longer the distance between the intended check-in data and the data observation date, the more uncertain it would appear. Consequently, predictions for both groups are slightly worse in the last two weeks than in the first two weeks.

As also revealed by Figure 2, the online reviews exhibit significant influence on the market demand of Airbnb listings. In general, an average listing with online reviews has a 15 per cent to 20 per cent higher probability of being booked than the listings with similar attributes but without online review. Since online review is frequently used by guests in evaluating the quality of the listings, the degree of information asymmetry is lower in the "with review" market segment than the "no review" counterpart. As a result, the guests would be more confident on the listing quality while booking a listing with online reviews.

Time constant, $c_{t}$, captures the pattern of listings' booking probability along time. Figure 3 shows the trend of the mean value of the series $\left\{c_{t}, c_{t+1}, \ldots\right\}$ for two subsamples with the shaded area representing the 99.5 per cent high density interval (HDI). For both subsamples, the series $\left\{c_{t}, c_{t+1}, \ldots\right\}$ decreases along time with significant spikes during weekends. This trend reveals the likelihood of a listing being booked decreases as the intended check-in date moves away from the data observation date. This phenomenon is most obvious within the first week away from the date of observation. The likelihood of a listing being booked is significantly higher during weekends in contrast to those during weekdays, which reveals a significant weekly seasonality in Airbnb booking.

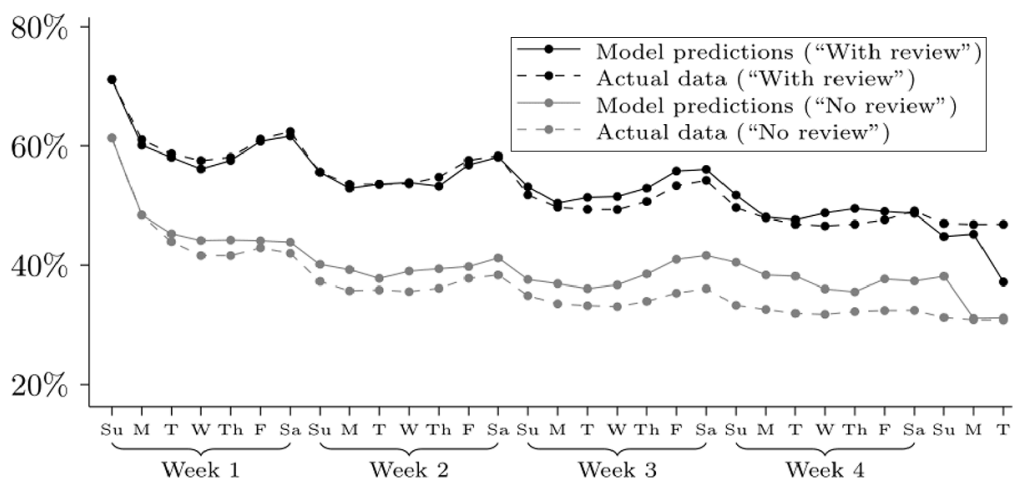

Figure 2. Model predictions of booking probability 
IJCHM

31,12

\section{8}

Figure 3.

The mean estimation of time effect

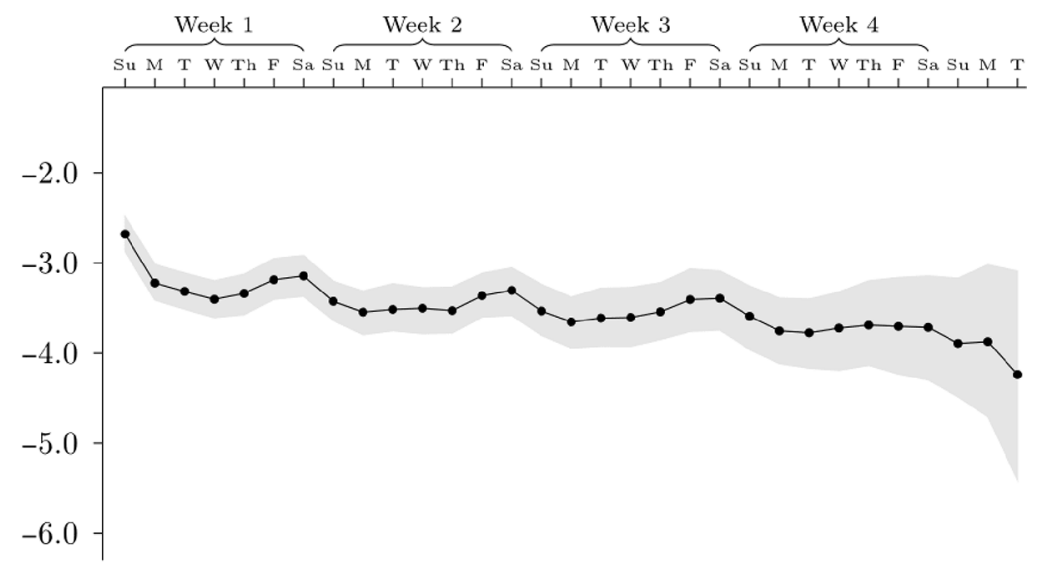

(a)

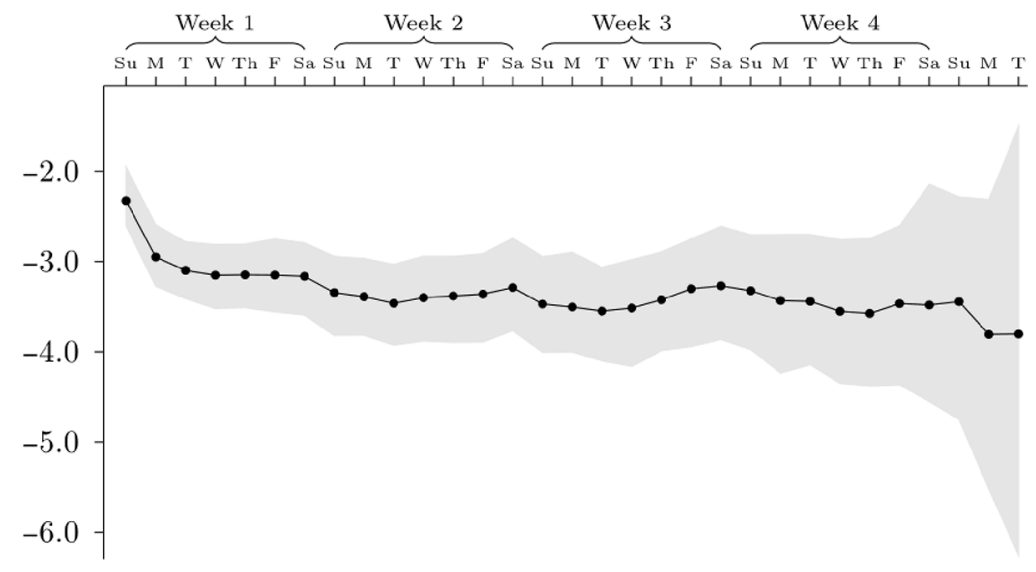

(b)

Notes: (a) Time effect of "With review" group; (b) time effect of "No review" group

\subsection{The influencing attributes of booking probability}

Tables I summarizes the posterior distribution of the parameters of functional attributes and Table II presents the same information for signal and dual attributes. The first column describes the attributes and the second to fifth columns present the estimation results of the "with review" group, where the mean and 99.5 per cent HDI of posterior distributions are provided in columns 2 to 4 . The fifth column shows the change in odds, assuming other attributes remain fixed. An attribute is considered to have significant influence on booking probability if the associated 99.5 per cent HDI excludes zero. Columns 6 to 9 present these results of the "no review" group. The tenth column $(p \neq)$ provides the credibility of the two posterior distributions of the "with review" group and the "no review" group being different. The calculation of this credibility largely follows Kruschke (2013) and the results are 


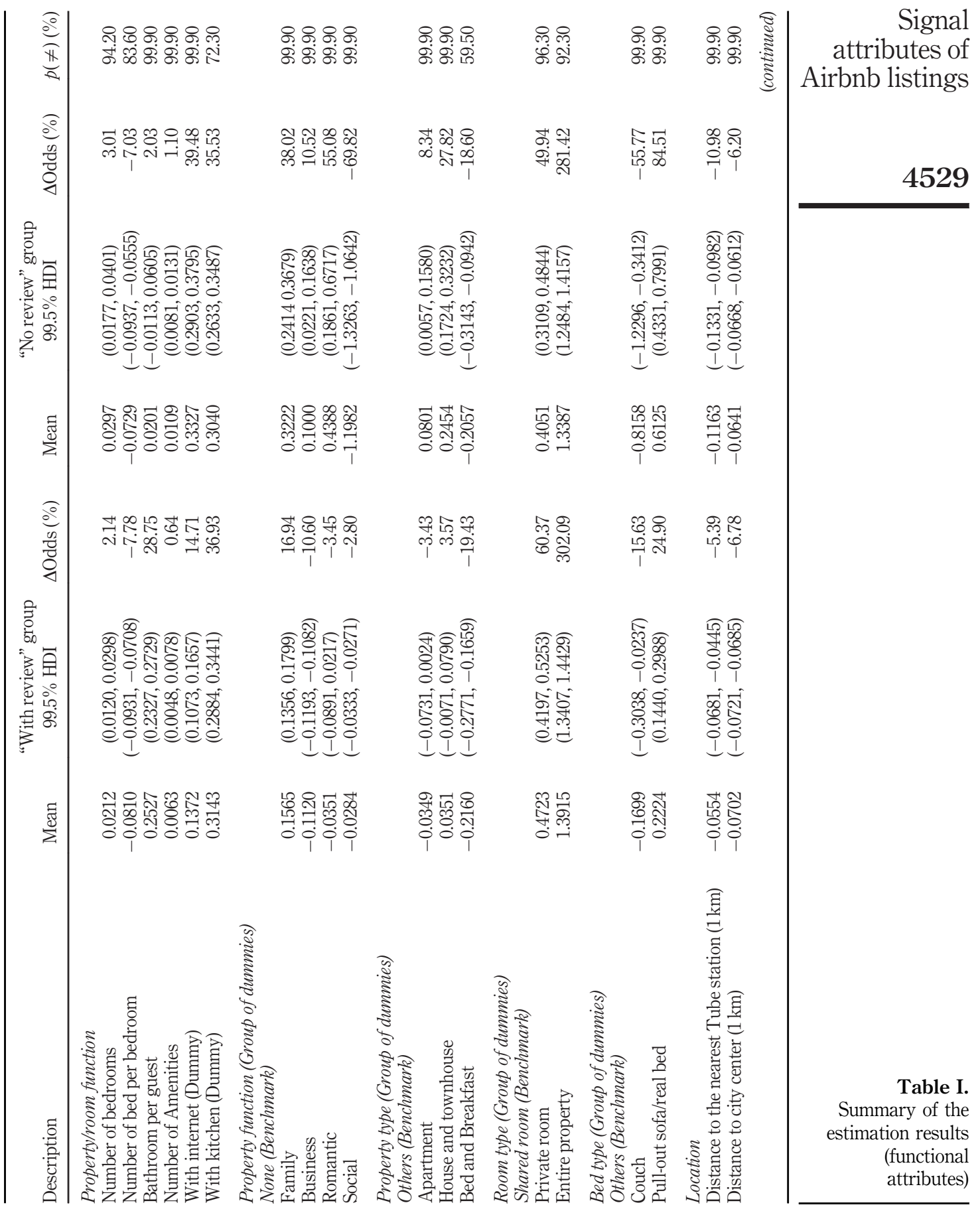


IJCHM

31,12

4530

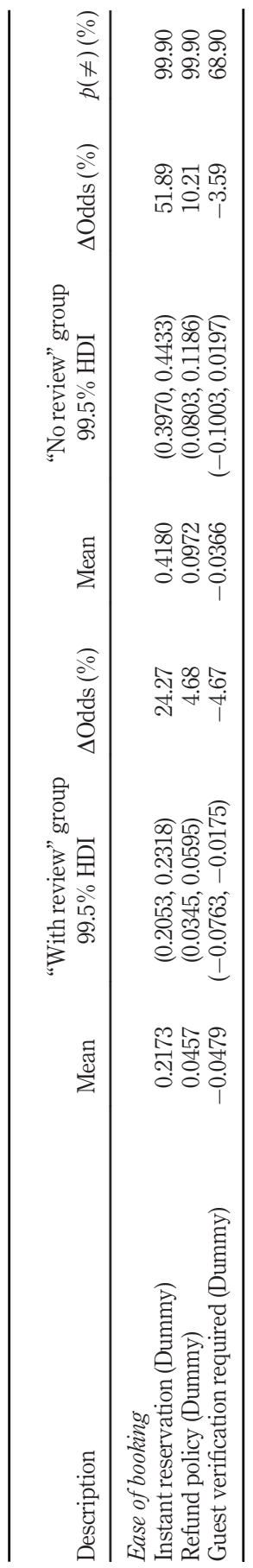

Table I. 


\begin{tabular}{|c|c|c|c|c|c|}
\hline 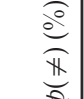 & $\begin{array}{l}\text { ৪ ৪ ৪ ৪ ৪ ৪ } \\
\text { ৪ু ৪ু ৪ু ৪ ৪ }\end{array}$ & $\begin{array}{l}\text { ৪. } \\
\text { ৪্ণ }\end{array}$ & 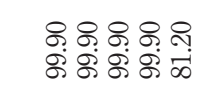 & $\begin{array}{l}\text { ৪) } \\
\text { চே }\end{array}$ & \\
\hline $\begin{array}{l}\frac{0}{0} \\
\frac{0}{0} \\
0 \\
0\end{array}$ & 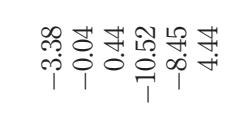 & ) & 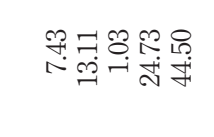 & 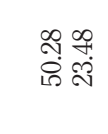 & \\
\hline 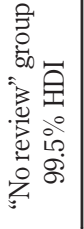 & 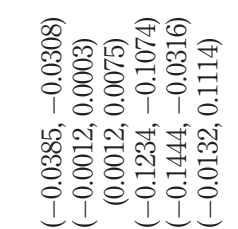 & 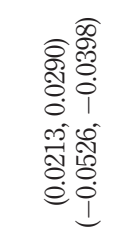 & 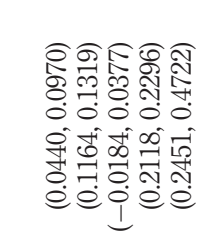 & 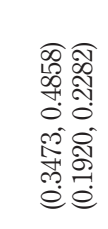 & \\
\hline$\stackrel{\bar{\Xi}}{\Sigma}$ & 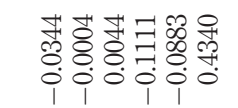 & 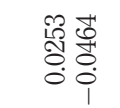 & 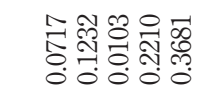 & 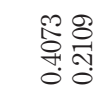 & \\
\hline $\begin{array}{l}\hat{0} \\
\frac{0}{8} \\
\overline{8}\end{array}$ & 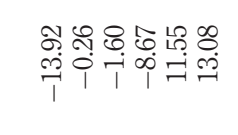 & 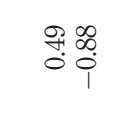 & 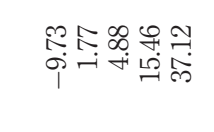 & 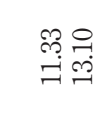 & 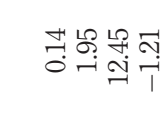 \\
\hline 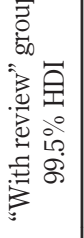 & 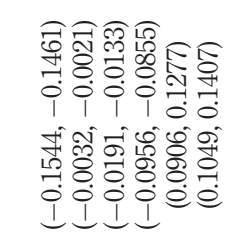 & 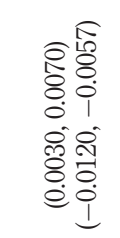 & 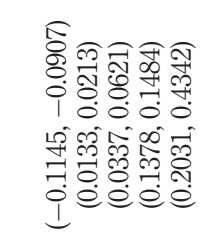 & 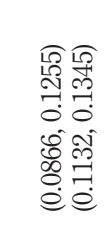 & 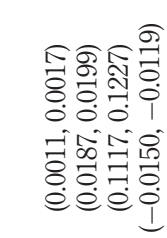 \\
\hline$\sum^{\stackrel{\Xi}{\Sigma}}$ & 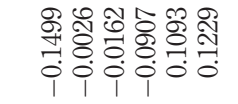 & 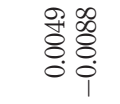 & 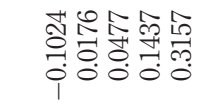 & 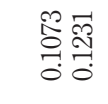 & 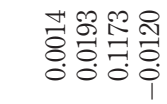 \\
\hline 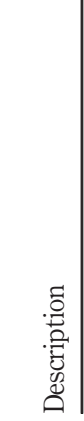 & 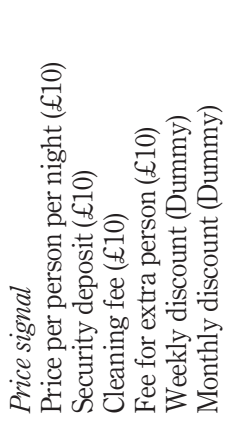 & 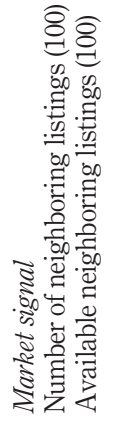 & 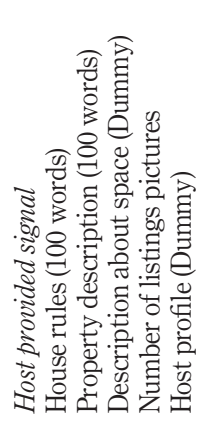 & 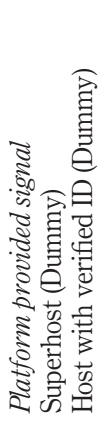 & 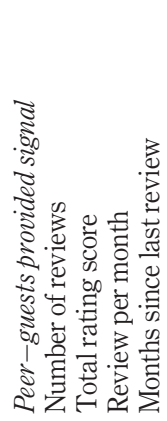 \\
\hline
\end{tabular}

Signal attributes of Airbnb listings

4531

Table II. Summary of the estimation results (signal attributes) 
IJCHM

31,12

discussed in terms of the change in odds. In statistics, the odds of an event reflect the likelihood that the event will take place. In the current context, the odds of a listing being booked are calculated by the ratio between the probability of the listing being booked and the probability of the listing being available. For continuous variables, the change in odds reflects the percentage change in the odds of a listing being booked when the independent variable changes by one unit. For dummy variables, it reflects the change in odds when the listing moves into a certain category (from the benchmark category in the case of group of dummy variables).

4.2.1 Functional attributes. Since accommodation is the primary product of Airbnb listings, property/room functionality is the area that has the most attributes. In general, large properties with more bedrooms and amenities are more popular. Each additional bedroom would boost up the booking odds for the "with review" listings by 2.14 per cent and for the "no review" listings by 3.01 per cent. Internet connection and kitchen could enhance the booking odds by 14.71 per cent and 36.93 per cent, respectively for the "with review" listings, and 39.48 per cent and 35.53 per cent, respectively for the "no review" listings. The dramatic change of odds led by internet connection indicates that the internet has become a necessity in our daily life. It is also reasonable that listing with kitchen attract more bookings, as cooking activity is a distinguished feature of Airbnb, which most hotel rooms cannot accommodate. Not every item provided by the hosts exhibit "the more is better" rule, an extra bed per bedroom makes the room crowded and less desirable. While social interaction is considered as a key motivation for tourist to use peer-to-peer accommodations (Lin et al., 2019; Tussyadiah and Pesonen, 2015), the current study found that privacy is still an important feature for Airbnb listings. In comparison with shared rooms, listings with a private room are preferred with additional odds of 60.37 per cent and 49.94 per cent for the two groups. Listings of entire property are preferred with additional odds of 302.09 per cent and 281.42 per cent for the two groups. That is, the host should always consider privacy while providing social interactive features in the property. A "social interaction" area should be appropriately separated from the bedrooms. Additional and private bathrooms are also favored (with additional odds of 28.75 per cent for the "with review" listings and 2.03 per cent for the "no review" listings), indicating a preference towards more private facilities. Listings with themes are more popular than the ones without themes. In particular, the theme of "family" is the most preferable. This result is not surprising as "Welcome Home" has long been a motto of Airbnb. Regarding the property type, houses and townhouses are more prominent in the market with additional odds of 3.57 per cent and 27.82 per cent for the two groups, whereas bed and breakfast accommodation are significantly disliked as they are not really in the style of Airbnb. When guests select listings, the ones with real beds are more likely to be booked than the ones with merely couches. This indicates a general desire on the basic living quality from the guests.

Geographical location of the listing is another crucial attribute. The location of accommodation can be generally related to the neighborhood environment, neighborhood convenience, and accessibility (Masiero et al., 2019). The location convenience of the listing could facilitate booking of the listing. Taking London as an example, $1 \mathrm{~km}$ away from the tube station will lead to a decline of the booking odds by 5.39 per cent and 10.98 per cent for the two groups. Whereas, $1 \mathrm{~km}$ away from the city center of London will decrease the booking odds by 6.78 per cent and 6.20 per cent for the two groups. For a metropolitan such as London, the city center could be crowded and noisy. However, for Airbnb guests, living in the city center and close to tube station means excellent neighborhood convenience and accessibility. These benefits would provide the guests with a flexible schedule, which enhances the traveling experience. The ease of the booking process also affects the odds of a 
listing being booked. A listing with instant booking policy could stimulate the booking odds by 24.27 per cent and 51.89 per cent for the "with review" listings and "no review" listings, respectively, in comparing with that of the listings without instant booking. Listings that need guest verification, either by ID or by phone, have the odds 4.67 per cent and 3.59 per cent lower than the listings without verification requirement. Flexible refund policy is also found to be well-received in the market for both groups.

The attributes discussed above describe one or more aspects of the Airbnb listings that are directly related to the consumption process of the guests. Judging by the credible level provided in the tenth column of Table I, it can be confidently concluded that the influence of each attribute on market demand for the "with review" listings are different from that for the "no review" listings. In terms of the direction of the influence, heterogeneity can be observed in a few attributes that are related to property function or theme. For the listings without any review, having a theme is generally considered as a benefit, whereas only the "family" type is preferred in the case of "with review" group. On average, the functional attributes for the "no review" group have 15.46 per cent larger marginal effects than those for the "with review" group. This observation can be well explained by the redistribution of attention: with the absence of online review, the guests would pay more attention to the attributes they have information on.

4.2.2 Dual attributes and signal attributes. While price is an essential attribute which is directly related to the consumption process of guests, it also exhibits strong signal effect in the information asymmetry scenario. Similar to other commodities, price is an important attribute that determines the sales of listings. A ten Pounds $(£ 10)$ decrease in the price per night per capita would increase the booking odds by 13.92 per cent and 3.38 per cent for the listings with and without online reviews, respectively. Compared with the "with review" group, the price sensitivity of the "no review" group is lower. While the market demand is negatively correlated with price in the classical economic theory, the strong price signaling effects for the "no review" group weakens the correlation. With the price considered as a signal on quality, the price increases for the "no review" group may not be a bad thing after all. Without any reviews in the online system, discounts on price would be a relatively ineffective marketing tool. While the discount on price provides the guests with economic benefits, it may also "discount" the confidence of the guests. For example, the weekly discounts provided by "no review" listings decrease the booking odds by 8.45 per cent, whereas the weekly discounts of "with review" listings have a significantly different effect, increasing the odds by 11.55 per cent. Extra charges, such as cleaning fees, fees for extra person, and security deposit generally keep the listing from being booked. Interestingly, extra charges on the cleaning fees could increase the booking odds for listings without review. This "counter-intuitive" result may be attributed to the scenario in which no accurate information could be retrieved from online reviews. Hence the charges on cleaning fees are used by guests as a strong signal on the cleanliness of the listing.

Some signal can be released through the market attributes. Regarding the total number of neighboring listings, every additional 100 neighbors would bring up the odds of the listing being booked by 0.49 per cent and 2.56 per cent for the two groups. This finding reflects the positive effect of the popularity of the region on booking probability. In terms of the number of available neighboring listings, the competition brought by others weaken the odds of a listing being booked (- -0.88 per cent and -4.54 per cent for the two groups). These two regional attributes have significantly stronger influence for the "no review" listings, emphasizing the signaling effects of regional popularity and market competition in that group. More precisely, a large number of listings within the region would deliver a message to the guests that the region is popular among the peer-guests due to some regional traits 
IJCHM

31,12

4534

(e.g. popular attractions, safe neighborhoods, or convenience transportation). Nonetheless, the available neighboring listings provide more options to the guests and also put the "no review" listings in an unfavorable position.

The Airbnb platform also allows hosts to post descriptions from different aspects to signal the quality of their listings. For listings with reviews, detailed description of the listings in terms of texts and pictures may enhance the booking odds by 1.77 per cent and 15.46 per cent, respectively, whereas the complication of house rules may decrease the booking odds by 9.73 per cent. In particular, the odds of the listing being booked for those with detailed description on the space are 4.88 per cent higher than that of the listing without such descriptions. In the case of "no review" group, any additional information guests could retrieve from the website, including house rules, would be beneficial for the booking odds (7.43 per cent, 13.11 per cent, 24.73 per cent for house rules, property description, and number of listing pictures, respectively). Without review information in the online system, guests are more likely to rely on information uploaded by hosts in the decision-making process. The detailed description provided by the host not only informs the guest regarding the functionality of the listing but also conveys the signal on how well and careful the host manages the property.

Similar to star ratings for hotels and Michelin stars for restaurants, the Airbnb platform honors good hosts with the "Superhost" title. Being a "Superhost", as suggested by Liang et al. (2017), has a very strong effect on the odds of the listings being booked. For the "with review" group, holding all other attributes fixed, the odds of being booked for a listing by a "Superhost" would be 11.33 per cent higher than that of properties listed by normal hosts. In the case of the "no review" group, the "Superhost" title would come from other properties that are listed by the host (hosts with multiple listings). The "Superhost" title would boost up the odds of the listing being booked by 50.28 per cent in such a case. In addition, detailed hosts' profile would enhance the odds by 37.12 per cent and 44.50 per cent for the "with review" group and "no review" group, respectively. If the identity of the host is verified, the odds of the listing being booked would increase by 13.10 per cent and 23.48 per cent for the two groups.

Consistent with the scenario in the hotel industry, online reviews are also valuable information that enhance the market demand of a listing. In the "with review" group, one additional review could boost up the booking odds by 0.14 per cent. The total rating of reviews, the frequency of reviews, and timeliness of the reviews further enhance this effect of word of mouth (1.95 per cent, 12.45 per cent, and 1.21 per cent, respectively). A peer-topeer review system is applied by Airbnb which incentivizes hosts and guests to give positive reviews to each other (Zervas et al., 2015). Keeping this system in mind, the quantity of the reviews is less influential than the actual contents of the reviews. This fact explains the limited effect of the number of reviews and relatively higher influence of other reviewrelated factors on the booking odds of Airbnb listings found in the current study. The frequency of the reviews also indicates the popularity of the listing and thus has a more important position in the decision-making process of guests than other review-related factors.

Confirmed by the credible level in the tenth column of Table II, the signal attributes reveal different influences on market demand for the "with review" group and the "no review" group. Price attributes, which can be labeled with both "functional" and "signal", have dual function in influencing the market demand. On one hand, as functional attributes, according to classical economic theory, an increase in price would discourage demand and a discount would do the opposite. On the other hand, however, the price signaling effect suggests a positive correlation between price and the perceived quality. The increase in 
price would lead to an increase in the perceived quality and then an increase in the market demand. In the current case of London, the information asymmetry is more severe in the case of "no review" group than that of the "with review" group. Therefore, it is more obvious in the "no review" group that the stronger price signaling effect offsets the negative correlation between price and market demand. On average, the price attributes of the "no review" group have 84.52 per cent smaller marginal effect than those of the "with review" group. Furthermore, signaling effects of the cleaning fee and weekly discount are so strong that the originally negative correlation between price and market demand is reversed.

In terms of other signal attributes, the signaling effect would enhance the marginal effect of the attributes. In particular, more text description of the property for the "no review" listings have a 639.53 per cent larger marginal effect in comparing with the case of "with review" listings. The "Superhost" title is 343.70 per cent more valuable for the listings without any online review than for the listings with online review. On average, the signal attributes for the "no review" group have 191.99 per cent larger marginal effects than those for the "with review" group. This number is far larger than the boost in the case of functional attributes (15.46 per cent). This comparison reveals the significant role of signal attributes for the "no review" listings.

\section{Implications and conclusions}

\subsection{Conclusions}

From a suppliers' perspective, the current study explores the signaling theory in the context of Airbnb booking probability by investigating the influence of listing attributes on the market demand of Airbnb listings in London. Binomial logistic model and sequential Bayesian updating approach are utilized in the analysis. For the 41,127 listed properties considered in the current study, daily booking data starting from 5 March 2017 up to 31 days ahead bookings are used to estimate the model. The findings of the current study show that, in addition to the functional attributes such as room functions and listing locations, signal attributes which are designated to indicate the quality of the listings are found to be important, especially for the listings without online review. The findings confirm previous literature (Liang et al., 2017; Xie and Mao, 2017) in the sense that information on the hosts are found to be important quality signals, including the "Superhost" title, hosts' profile, and verification status. In addition, price of the listings, extra charges (such as cleaning fees), regional competitiveness and popularity, and house rules also emerge as important signals that indicate the quality of the listings and influence the booking probability. In general, comparing with other types of listings, an entire house/ townhouse with real beds, more bedrooms, bathrooms, and amenities, particularly with internet and kitchen, is more likely to be booked by guests. Geographical factors, such as regional competition, regional popularity, and geographical convenience also make the listing stand out from the crowd.

\subsection{Theoretical implications}

The originality of the study is the exploration of quality signals in Airbnb context which is also an expansion of the signaling theory applications. Although the signal effect has been brought up by previous literature (Chen and Xie, 2017; Li et al., 2016), the current study further examines it from a more comprehensive perspective. A distinctive group of signal attributes is explicitly identified and discussed. In absence of online reviews, which is a major information source for the guests, signal attributes are found to be critical for attracting market demand for Airbnb listings. However, the importance of signal attributes depreciates when the number of reviews accumulates. A decremental margin of 191.99 per 
IJCHM

31,12

cent is observed on average for the signal attributes, once the listings move from the "no review" group into the "with review" group. Under the circumstances, guests retrieve information from online reviews and pay less attention to the signals. In contrast, the depreciation in the marginal effect is much less for the attributes that are actually consumed by the guests. A decremental margin of 15.46 per cent is found on average for the functional attributes for the listings which move from the "no review" group into the "with review" group. The estimation of time effect also consolidates the "weekly seasonality" feature of the property booking in the Airbnb industry. Methodologically, the sequential Bayesian updating approach, which is very convenient for the rich data feature of the sharing economy literature, is introduced into the hospitality literature for the first time.

\subsection{Practical implications}

Managerial implications also emerge from these research findings. Strategically Airbnb entries need to provide the sense of safety and security that consumer expect from accommodation establishments. They also need to demonstrate that they have large space and provide differentiated experiences, often enabling guests to stay like a local. Therefore, hosts should upload more information regarding the property and boost the popularity of the listing. Information should be provided for both the property and the context/location of the property demonstrating the attractiveness of the proposition. This is for listings currently without review information and also for new properties or for those off the bitter track. When the listing is initiated without any online review, the host should work on signal attributes to reduce information asymmetry. Visual information in terms of photographs, links and other clues can reduce the perceived uncertainty and enhance consumer confidence. This is critical as in the hospitality alternatives consumers can trust brand name propositions and standards, such as Hilton, Marriott, or Jumeirah. Airbnb properties rely almost exclusively on near real time descriptions to support (Buhalis and Sinarta, 2019). Strategically, the information provided in both textual and visual forms need to reduce ambiguity and address areas of criticism. For example, for the listings without reviews on the cleanliness, the use of cleaning fee charges as well as photographs that demonstrate that property is spotless can be useful. Nonetheless, as the information asymmetry reduces with the increasing number of online reviews, the effect of signal attributes depreciates fast.

The host should also carefully monitor the review status of his/her listings to convey quality information and to respond to all comments both negative and positive as well as work on functional attributes. Since guests are more likely to book an entire property or private rooms, the host should enhance the privacy of the listing. Capitalizing on feedbacks and understanding customer needs and guest priorities within the context of the property can offer exceptional service to guests. Hosts can offer more convenient amenities and policies. Facilities such as internet connection and instant reservation as well as amenities such as bicycles, baby strollers, or umbrellas may be appropriate and desirable additional services that guests may appreciate. The findings of this study could be utilized to conduct revenue simulation in what-if scenarios to ensure that profitability is maximized through yield management and ancillary services. Such a simulation can be useful to the current and potential hosts in property management and strategy planning. Finally, public sector and regulators can use the findings to ensure that there is harmony between the formal hospitality sector and the Airbnb type of accommodation and to create the appropriate regulatory and investment environment to maximize the benefits for all the stakeholders at the destination. 
This study is not without limitations. Due to data limitations, the effects of local hotels on Airbnb listings are omitted from the estimation. It would be interesting to integrate the interaction effect between Airbnb listings and traditional hotels in the model. The integration could further improve the predictability of the current model. Another limitation is that the model only examined data on London, which is a mature market of Airbnb. More practical implications could be found once the model is applied to an emerging market in future studies. In future studies, it is also valuable to integrate the emerging brand in Airbnb market such as "Airbnb Plus" and other psychological and sociological factors into the model and provide a more updated and comprehensive understanding of Airbnb market.

\section{References}

Abrate, G., Capriello, A. and Fraquelli, G. (2011), "When quality signals talk: evidence from the Turin hotel industry”, Tourism Management, Vol. 32 No. 4, pp. 912-921.

Akerlof, G.A. (1970), “The market for 'lemons': quality uncertainty and the market mechanism”, The Quarterly Journal of Economics, Vol. 84 No. 3, pp. 488-500.

$\mathrm{Au}, \mathrm{N}$., Buhalis, D. and Law, R. (2014), "Online complaining behavior in mainland China hotels: the perception of Chinese and Non-Chinese customers", International Journal of Hospitality and Tourism Administration, Vol. 15 No. 3, pp. 248-274.

Buhalis, D. and O'Connor, P. (2005), "Information communication technology revolutionizing tourism", Tourism Recreation Research, Vol. 30 No. 3, pp. 7-16.

Buhalis, D. and Sinarta, Y. (2019), "Real-time co-creation and nowness service: lessons from tourism and hospitality", Journal of Travel and Tourism Marketing, Vol. 36 No. 5, pp. 563-582.

Callan, R.J. (1995), "Hotel classification and grading schemes, a paradigm of utilisation and user characteristics", International Journal of Hospitality Management, Vol. 14 Nos 3/4, pp. 271-283.

Callan, R.J. (1998), “Attributional analysis of customers' hotel selection criteria by UK grading scheme categories”, Journal of Travel Research, Vol. 36 No. 3, pp. 20-34.

Casaló, L.V., Flavián, C., Guinalíu, M. and Ekinci, Y. (2015), "Do online hotel rating schemes influence booking behaviors?”, International Journal of Hospitality Management, Vol. 49, pp. 28-36.

Chen, C.C. and Schwartz, Z. (2008), "Timing matters: travelers' advanced-booking expectations and decisions", Journal of Travel Research, Vol. 47 No. 1, pp. 35-42.

Chen, Y. and Xie, K.L. (2017), "Consumer valuation of airbnb listings: a hedonic pricing approach", International Journal of Contemporary Hospitality Management, Vol. 29 No. 9, pp. 2405-2424.

Chen, C.C., Schwartz, Z. and Vargas, P. (2011), "The search for the best deal: how hotel cancellation policies affect the search and booking decisions of deal-seeking customers", International Journal of Hospitality Management, Vol. 30 No. 1, pp. 129-135.

Chow, K.E., Garretson, J.A. and Kurtz, D.L. (1995), “An exploratory study into the purchase decision process used by leisure travelers in hotel selection", Journal of Hospitality and Leisure Marketing, Vol. 2 No. 4, pp. 53-72.

Chu, R.K. and Choi, T. (2000), "An importance-performance analysis of hotel selection factors in the Hong Kong hotel industry: a comparison of business and leisure travelers", Tourism Management, Vol. 21 No. 4, pp. 363-377.

Dogru, T. and Pekin, O. (2017), "What do guests value most in airbnb accommodations? An application of the hedonic pricing approach", available at: https://vtechworks.lib.vt.edu/bitstream/handle/ 10919/79602/What-do-guests-value-most-in-Airbnb-accommodations_An-application-of-thehedonic-pricing-approach_Dogru-Pekin.pdf?sequence=1 (accessed 19 April 2019). 
IJCHM 31,12

Dolnicar, S. and Otter, T. (2003), "Which hotel attributes matter? A review of previous and a framework for future research", in Griffin, T. and Harris, R. (Eds), Proceedings of the 9th Annual Conference of the Asia Pacific Tourism Association (APTA), University of Technology Sydney, Sydney, Vol. 1, pp. 176-188.

Ert, E., Fleischer, A. and Magen, N. (2016), "Trust and reputation in the sharing economy: the role of personal photos in airbnb”, Tourism Management, Vol. 55, pp. 62-73.

Gibbs, C., Guttentag, D., Gretzel, U., Morton, J. and Goodwill, A. (2018), "Pricing in the sharing economy: a hedonic pricing model applied to airbnb listings", Journal of Travel and Tourism Marketing, Vol. 35 No. 1, pp. 46-56.

Guizzardi, A., Pons, F.M.E. and Ranieri, E. (2017), "Advance booking and hotel price variability online: any opportunity for business customers?", International Journal of Hospitality Management, Vol. 64, pp. 85-93.

Gutt, D. and Herrmann, P. (2015), "Sharing means caring? Hosts' price reaction to rating visibility", ECIS 2015 Research-in-Progress Papers, Paper 54.

Henley, J.A., Jr, Cotter, M.J. and Herrington, J.D. (2004), "Quality and pricing in the hotel industry: the Mobil 'star' and hotel pricing behavior", International Journal of Hospitality and Tourism Administration, Vol. 5 No. 4, pp. 53-65.

Jacoby, J., Olson, J.C. and Haddock, R.A. (1971), "Price, brand name, and product composition characteristics as determinants of perceived quality", Journal of Applied Psychology, Vol. 55 No. 6, pp. 570-579.

Kim, W.G. and Park, S.A. (2017), "Social media review rating versus traditional customer satisfaction: which one has more incremental predictive power in explaining hotel performance?", International Journal of Contemporary Hospitality Management, Vol. 29 No. 2, pp. 784-802.

Kostyra, D.S., Reiner, J., Natter, M. and Klapper, D. (2016), "Decomposing the effects of online customer reviews on Brand, price, and product attributes", International Journal of Research in Marketing, Vol. 33 No. 1, pp. 11-26.

Kruschke, J.K. (2013), "Bayesian estimation supersedes the $t$ test", Journal of Experimental Psychology: General, Vol. 142 No. 2, pp. 573-603.

Ladhari, R. and Michaud, M. (2015), "eWOM effects on hotel booking intentions, attitudes, trust, and website perceptions”, International Journal of Hospitality Management, Vol. 46, pp. 36-45.

Law, R. and Wong, R. (2010), “Analysing room rates and terms and conditions for the online booking of hotel rooms", Asia Pacific Journal of Tourism Research, Vol. 15 No. 1, pp. 43-56.

Li, Y., Pan, Q., Yang, T. and Guo, L. (2016), "Reasonable price recommendation on airbnb using multiscale clustering", Control Conference (CCC), 2016 35th Chinese, IEEE, pp. 7038-7041.

Liang, S., Schuckert, M., Law, R. and Chen, C.C. (2017), "Be a 'superhost': the importance of badge systems for peer-to-peer rental accommodations", Tourism Management, Vol. 60, pp. 454-465.

Lin, P.M., Fan, D.X., Zhang, H.Q. and Lau, C. (2019), "Spend less and experience more: understanding tourists' social contact in the airbnb context", International Journal of Hospitality Management, Vol. 83, pp. 65-73.

Masiero, L., Yang, Y. and Qiu, R.T.R. (2019), "Understanding hotel location preference of customers: comparing random utility and random regret decision rules", Tourism Management, Vol. 73, pp. 83-93.

Möhlmann, M. (2016), "Digital trust and peer-to-peer collaborative consumption platforms: a mediation analysis”, SSRN Working Paper 2813367, available at: http://papers.ssrn.com/sol3/papers.cfm? abstract_id=2813367 (accessed 19 January 2018).

Nicolau, J.L. and Sellers, R. (2010), "The quality of quality awards: diminishing information asymmetries in a hotel chain", Journal of Business Research, Vol. 63 No. 8, pp. 832-839.

Öğüt, H. and Onur Taş, B.K. (2012), "The influence of internet customer reviews on the online sales and prices in hotel industry", The Service Industries Journal, Vol. 32 No. 2, pp. 197-214. 
Oravecz, Z., Huentelman, M. and Vandekerckhove, J. (2016), "Sequential bayesian updating for big data", in Jones, M.N. (Ed.), Big Data in Cognitive Science: From Methods to Insights, UC Irvine, CA, pp. 13-33.

Oskam, J. and Boswijk, A. (2016), “Airbnb: the future of networked hospitality businesses”, Journal of Tourism Futures, Vol. 2 No. 1, pp. 22-42.

Ponte, E.B., Carvajal-Trujillo, E. and Escobar-Rodriguez, T. (2015), "Influence of trust and perceived value on the intention to purchase travel online: integrating the effects of assurance on trust antecedents", Tourism Management, Vol. 37, pp. 286-302.

Rahimi, S., Liu, X. and Andris, C. (2016), "Hidden style in the city: an analysis of geolocated airbnb rental images in ten major cities", Proceedings of the 2nd ACM SIGSPATIAL Workshop on Smart Cities and Urban Analytics, ACM, p. 7.

Senecal, S. and Nantel, J. (2004), "The influence of online product recommendations on consumers' online choices", Journal of Retailing, Vol. 80 No. 2, pp. 159-169.

Song, H., Lin, S., Witt, S.F. and Zhang, X. (2011), "Impact of financial/economic crisis on demand for hotel rooms in Hong Kong", Tourism Management, Vol. 32 No. 1, pp. 172-186.

Spence, M. (1973), “Job market signaling”, The Quarterly Journal of Economics, Vol. 87 No. 3, pp. 355-374.

Teubner, T., Hawlitschek, F. and Dann, D. (2017), "Price determinants on airbnb: how reputation pays off in the sharing economy", Journal of Self-Governance and Management Economics, Vol. 5 No. 4 , pp. 53-80.

Tsao, W.C., Hsieh, M.T., Shih, L.W. and Lin, T.M. (2015), "Compliance with eWOM: the influence of hotel reviews on booking intention from the perspective of consumer conformity", International Journal of Hospitality Management, Vol. 46, pp. 99-111.

Tussyadiah, I.P. and Pesonen, J. (2015), "Impacts of peer-to-peer accommodation use on travel patterns", Journal of Travel Research, Vol. 55 No. 8, pp. 1022-1040.

Wang, D. and Nicolau, J.L. (2017), "Price determinants of sharing economy-based accommodation rental: a study of listings from 33 cities on airbnb.com”, International Journal of Hospitality Management, Vol. 62, pp. 120-131.

Wang, L., Law, R., Guillet, B.D., Hung, K. and Fong, D.K.C. (2015), "Impact of hotel website quality on online booking intentions: eTrust as a mediator", International Journal of Hospitality Management, Vol. 47, pp. 108-115.

Wolinsky, A. (1983), "Prices as signals of product quality", The Review of Economic Studies, Vol. 50 No. 4, pp. 647-658.

Wu, D.C., Song, H. and Shen, S. (2017), "New developments in tourism and hotel demand modeling and forecasting", International Journal of Contemporary Hospitality Management, Vol. 29 No. 1, pp. 507-529.

Xie, K.L. and Mao, Z. (2017), "The impacts of quality and quantity attributes of airbnb hosts on listing performance", International Journal of Contemporary Hospitality Management, Vol. 29 No. 9, pp. 2240-2260.

Yang, Y., Mueller, N.J. and Croes, R.R. (2016), "Market accessibility and hotel prices in the caribbean: the moderating effect of quality-signaling factors", Tourism Management, Vol. 56, pp. 40-51.

Yang, Y., Wong, K.K. and Wang, T. (2012), "How do hotels choose their location? Evidence from hotels in beijing", International Journal of Hospitality Management, Vol. 31 No. 3, pp. 675-685.

Yu, Y., Guo, X., Zhang, Y. and Zhao, H. (2016), “Online review impacts on hotel online booking decision”, 6th International Conference on Electronic, Mechanical, Information and Management Society.

Zervas, G. Proserpio, D. and Byers, J. (2015), “A first look at online reputation on airbnb, where every stay is above average", available at: https://ssrn.com/abstract=2554500 (accessed 19 January 2018).

Zhao, X., Wang, L., Guo, X. and Law, R. (2015), "The influence of online reviews to online hotel booking intentions", International Journal of Contemporary Hospitality Management, Vol. 27 No. 6, pp. 1343-1364. 
IJCHM
31,12

Appendix 1

Listing attributes (Numerical)

Number of bedrooms

Number of bed per bedroom

Bathroom per guest

Number of Amenities

Distance to the nearest Tube

station (km)

Distance to city center $(\mathrm{km})$

Price per person per night $(£)$

Security deposit $(£)$

Cleaning fee $(£)$

Fee for extra person $(£)$

Number of neighboring listings

Available neighboring listings

House rules

Property description

Number of listing pictures

Number of reviews

Total rating score

Review per month

Months since last review

\section{Listing Attributes}

(Categorical and Dummies)

With internet

With kitchen

Property function

Property type

Room type

Bed type

Instant reservation

Refund policy

Guest verification required

Weekly discount

Monthly discount

Table AI.

Descriptive statistics of listing attributes ("with review" listings)
Description about space

Host profile

Superhost

Host with verified ID

Total number of listings ("With review")

\section{Proportion}

Yes $=97.36 \% ;$ No $=2.64 \%$

Yes $=92.19 \% ; \mathrm{No}=7.81 \%$

Family $=1.98 \%$; Business $=2.70 \% ;$ Romantic $=0.99 \% ;$ Social $=2.03 \%$;

Standard $=92.30 \%$

Apartment $=72.12 \%$; House and Townhouse $=23.49 \%$; B B,

Guesthouse, and Hostel $=2.55 \%$; Others $=1.83 \%$

Shared room $=1.24 \%$; Private room $=47.03 \%$; Entire home $/$ apartment $=$ $51.73 \%$

Real Bed $=99.18 \% ;$ Couch $/$ Futon $=0.21 \% ;$ Others $=0.61 \%$

Yes $=23.22 \%$; No $=76.78 \%$

Yes $=51.39 \% ;$ No $=48.61 \%$

Yes $=4.73 \% ;$ No $=95.27 \%$

Yes $=17.46 \% ;$ No $=82.54 \%$

Yes $=17.57 \% ;$ No $=82.34 \%$

Yes $=77.32 \% ;$ No $=22.68 \%$

Yes $=99.78 \% ;$ No $=0.22 \%$

Yes $=12.56 \% ;$ No $=87.44 \%$

Yes $=67.50 \% ; \mathrm{No}=32.50 \%$

30112 


\begin{tabular}{|c|c|c|c|c|c|c|}
\hline Listing attributes (Numerical) & Mean & $\mathrm{SD}$ & Median & Min & $\operatorname{Max}$ & Airbnb listings \\
\hline Number of bedrooms & 1.36 & 0.91 & 1 & 0 & 10 & \\
\hline Number of bed per bedroom & 1.22 & 0.62 & 1 & 0.1 & 16 & \\
\hline Bathroom per guest & 0.57 & 0.36 & 0.5 & 0 & 5 & \\
\hline Number of Amenities & 12.66 & 4.96 & 13 & 2 & 29 & 4541 \\
\hline Distance to the nearest Tube station $(\mathrm{km})$ & 0.83 & 0.59 & 0.7 & 0 & 6.76 & \\
\hline Distance to city center (km) & 7.62 & 4.39 & 6.59 & 0.06 & 28.6 & \\
\hline Price per person per night $(£)$ & 38.19 & 94.69 & 30 & 0.75 & 6880 & \\
\hline Security deposit $(£)$ & 112.03 & 240.99 & 0 & 0 & 4098 & \\
\hline Cleaning fee $(£)$ & 20.69 & 36.51 & 0 & 0 & 517 & \\
\hline Fee for extra person $(£)$ & 5.71 & 13.41 & 0 & 0 & 240 & \\
\hline Number of neighboring listings & 8555.14 & 4725 & 9428 & 5 & 15813 & \\
\hline Available neighboring listings & 4308.77 & 2616.87 & 4586 & 0 & 11380 & \\
\hline House rules & 0.17 & 0.33 & 0 & 0 & 2.01 & \\
\hline Property description & 1.98 & 1.66 & 1.57 & 0 & 12.73 & \\
\hline Number of listing pictures & 3.57 & 1.05 & 4 & 1 & 4 & \\
\hline
\end{tabular}

\section{Listing Attributes (Categorical} and Dummies)

With internet

With kitchen

Property function

Property type

Room type

Bed type

Instant reservation

Refund policy

Guest verification required

Weekly discount

Monthly discount

Description about space

Host profile

Superhost

Host with verified ID

Total number of listings ("No review")

\section{Proportion}

Yes $=91.24 \% ; \mathrm{No}=8.76 \%$

Yes $=88.92 \% ;$ No $=11.08 \%$

Family $=0.27 \%$; Business $=0.42 \%$; Romantic $=0.15 \% ;$ Social $=$ $0.36 \% ;$ Standard $=98.80 \%$

Apartment $=67.53 \% ;$ House and Townhouse $=27.78 \% ; \mathrm{B} \& \mathrm{~B}$,

Guesthouse, and Hostel $=2.49 \%$; Others $=2.21 \%$

Shared room $=2.04 \%$; Private room $=53.32 \%$; Entire home/ apartment $=44.63 \%$

Real Bed $=99.46 \% ;$ Couch $/$ Futon $=0.16 \%$; Others $=0.38 \%$

Yes $=26.53 \%$; No $=73.47 \%$

Yes $=66.37 \% ;$ No $=33.63 \%$

Yes $=2.00 \% ;$ No $=98.00 \%$

Yes $=6.00 \% ; \mathrm{No}=94.00 \%$

Yes $=5.34 \% ; \mathrm{No}=94.66 \%$

Yes $=50.60 \% ;$ No $=49.40 \%$

Yes $=99.18 \% ;$ No $=0.82 \%$

Yes $=2.20 \% ;$ No $=97.80 \%$

Yes $=48.34 \% ;$ No $=51.66 \%$

11012
Table AII.

Descriptive statistics of listing attributes ("No review" listings) 
IJCHM

31,12

4542

\section{About the authors}

Bin $\mathrm{Yao}$ is a $\mathrm{PhD}$ candidate in the School of Economics at the Liaoning University. She received MA in Economics from the Vanderbilt University, USA, and an honorary degree of BMOS (Bachelor of Management and Organizational Studies) from the University of Western Ontario, Canada. Her research interests include economic impact of tourism industry, tourism firm performance, and wine economics.

Richard T.R. Qiu is an Assistant Professor in the Department of Integrated Resort and Tourism Management, Faculty of Business Administration at University of Macau. He is a $\mathrm{PhD}$ graduate of the Hong Kong Polytechnic University. His research interests are tourism economics, tourist choice analysis and tourism demand forecasting. Richard T.R. Qiu is the corresponding author and can be contacted at: richardqiu@um.edu.mo

Daisy X.F. Fan is a Lecturer in tourism and hospitality at Bournemouth University, UK. Her research interests include tourist-host social contact, tourists' ethnocentrism, cultural distance and cruise travel. She is a PhD graduate of the Hong Kong Polytechnic University and worked in a hotel consulting company in Hong Kong prior to her study.

Anyu Liu is a Lecturer in hospitality management in the School of Hospitality and Tourism Management at University of Surrey. His research interests are in the areas of applied economics in tourism and hospitality and tourism and hospitality demand modeling and forecasting.

Professor Dimitrios Buhalis is a Strategic Management and Marketing expert with specialization in Information Communication Technology applications in the Tourism, Travel, Hospitality and Leisure industries. He is the Head of Department of Tourism and Hospitality, Director of the eTourism Lab and Deputy Director of the International Centre for Tourism and Hospitality Research, at Bournemouth University in England. His current research focus includes: Smart Tourism, Social Media Context and Mobile Marketing (SoCoMo), Augmented Reality, Experience Management and Personalisation, Reputation and Social Media Strategies, Accessible and Special Diet (Alergens) Tourism.

For instructions on how to order reprints of this article, please visit our website: 